\title{
On the Safe Navigation in Confined Water Including the Effect of Wind and Current
}

\author{
by Chun-Ki Lee, Member Katsuro Kijima, Member
}

\begin{abstract}
Summary
This paper is mainly concerned with the safe navigation between deep-drafted vessels moving each other in restricted waterways under the external force, such as wind or current. The manoeuvring simulation for model ship was conducted to find out an appropriate safe speed and distance between ships, which is required to avoid sea accident from the viewpoint of marine safety. The conditions were varied, such as velocity ratios, ship-length ratios, and separate parameters including the direction and velocity of wind and current. From the inspection of this investigation, it indicates the following result. Firstly, for the case of ship-size estimation, the lateral separation between two ships is more required for the small vessel, compared to the large vessel regardless of the effect of external force. Secondly, the lateral distance between ships are necessarily required for the velocity ratio of 1.2 , compared to the cases of 0.6 and 1.5. Thirdly, in case of proximal navigation between ships under the wind and current, the low-speed vessel is potentially hazardous because the rudder force of low-speed vessel needed for steady-state course-keeping is not sufficient, compared to the high-speed vessel.
\end{abstract}

\section{Introduction}

When a deep-draft vessel navigates in restricted waterways, such as in a harbour, or in a narrow channel it usually does so close to other ships. The problem of ship manoeuvring due to the inherently restricted nature of these waterways has always been of major concern not only for naval architects and ship operators but also of engineers who will design future waterways from the view-

* Kyushu University

Received 8th July 2002

Read at the Autumn meeting 14, 15th Nov. 2002 point of marine safety. The increasing number of ship collisions and the resulting ship grounding, etc., have led to a massive effort of improving ship manoeuvrability performance because the situation in these areas is being made more complex by local currents, changing tides, confined maneuvering boundaries, and considerable hydrodynamic effects of ships moving closer each other. In particular, proximal navigation of large vessels including overtaking, head-on situation, and congested vessel traffic in these waterways under the external force, such as wind or current is potentially hazardous. Thus, it is extremely important that the ship operator should be able to maintain full control of the ship during operations. For this to be possible, the hydrodynamic interaction 
between ships in restricted waterways should be properly understood, and the works on this part have been reported for the past years. But, the detailed knowledge on maneuvering characteristics for the safe navigation while avoiding terrible collision between ships, particularly under the wind and current, is still being required to prevent marine disasters. The main subject of this paper is to investigate appropriate safe distance and speed for safe navigation to avoid calamities among the vessels operating in the proximity, under the external force, such as wind or current in restricted waterways.

A large number of papers have been described on the hydrodynamic interaction between ships. Thus, some improved results were obtained. Yeung[1] studied on the interactions of slender ships in shallow water. Also, Yeung et al. [2] analyzed hydrodynamic interactions acting on a ship moving near the fixed obstacles. Similar works were also reported by Davis [3]. Kijima et al. [4] studied on the interaction effects between two ships in the proximity of bank wall. Kijima et al. [5] studied on maneuvering motion of a ship in the proximity of bank wall. Yasukawa [6] studied on the bank effect on ship maneuverability in a channel with varying width. Meanwhile, Lee et al. [7] reported experimental results on the sidewall effect on the hydrodynamic forces acting on a vessel in restricted waterways. Also, Lee et al. [8] obtained the evaluation on the safe navigation including the interaction forces between ships, and between ship and some fixed obstacles under various conditions.

In the present paper, the emphasis is on the appropriate safe speed and distance between ships required to avoid sea accident and on the guideline to the design and operation of the ship-waterway system from the viewpoint of marine safety under the wind and current.

\section{Theoretical backrounds}

The coordinate systems fixed on each ship and on the earth are shown by $o_{i}-x_{i} y_{i}(i=1,2)$ and $o-x y$, respectively in Fig.1. Consider two vessels designated as ship 1 and ship 2 moving at speed $U_{i}(i=1,2)$ in an inviscid fluid of finite water depth h. $S_{P 12}$ and $S_{T 12}$ represent the lateral and longitudinal distances between ship 1 and ship 2 in Fig.1. $V_{W}, V_{c}, \nu, \alpha$ mean the wind velocity, current velocity, wind direction and current direction, respectively. Both calculation methods and theoretical backgrounds related in this were reported in the previous research work [8], but non-dimensional expression for the lateral force, $C F_{i}$, and yawing moment, $C M_{i}$, affecting upon two vessels is given by

$$
C F_{i}=\frac{F_{i}}{\frac{1}{2} \rho L_{i} d_{i} U_{i}{ }^{2}} \quad, \quad C M_{i}=\frac{M_{i}}{\frac{1}{2} \rho L_{i}{ }^{2} d_{i} U_{i}{ }^{2}}
$$

where $L_{i}$ is the ship length of ship $i$ and $d_{i}$ the draft of ship $i . \rho$ is the water density.

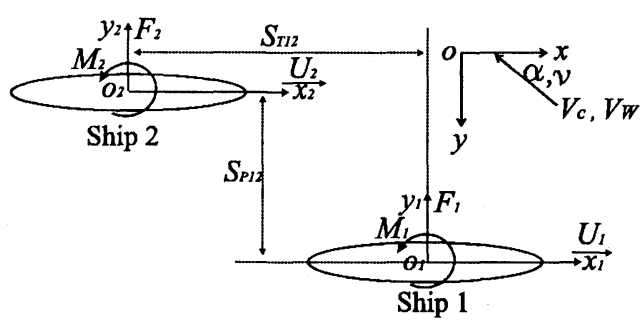

Fig. 1 Coordinate systems

\section{Conditions of calculation and equations of motion under the external force}

In case where the wind and current velocity are very small, compared to the advance speed of the ship, it is possible to turn the ship to the left or right with moderate helm angle. However, as the wind or current velocity becomes large, it becomes difficult to turn her to the direction as one demands. So, the manoeuvering motion between ships while overtaking in congested areas under the current and wind is potentially hazardous. A parametric study on the numerical investigations has been conducted on the general cargo ship as a model vessel as shown in Table 1 and Table 2, which both ship 1 and ship 2 are always similar form. A typical overtaking condition was investigated as shown in Fig.1. For the cases of different ratios of $0.5,1.0$ and 1.18 in $L_{2} / L_{1}$ and for the cases of $0.6,1.2$ and 1.5 in $U_{2} / U_{1}$ as the parameters as shown in Table 2, the hydrodynamic interaction forces between two ships in open sea were reported 
in the previous research work [8]. As shown in Table 3 , for the cases of external force, the wind direction $(\nu)$ and velocity $\left(V_{W}\right)$ were considered from $0^{\circ}$ to $350^{\circ}$ and $10 \mathrm{~m} / \mathrm{s}$, respectively, and the current direction $(\alpha)$ was considered as $0^{\circ}$ and $180^{\circ}$, and also current velocity $\left(V_{c}\right)$ was considered as $4 \mathrm{kt}$.

Table 1 Principal particulars of model ship 1

\begin{tabular}{|c|c|}
\hline$L(\mathrm{~m})$ & 2.5 \\
\hline$B(\mathrm{~m})$ & 0.419 \\
\hline$d(\mathrm{~m})$ & 0.140 \\
\hline$C_{B}$ & 0.698 \\
\hline Scale & $1 / 62$ \\
\hline
\end{tabular}

Table 2 Types with parameters $L_{2} / L_{1}$ and $U_{2} / U_{1}$

\begin{tabular}{|c|c|c|}
\hline \multirow{2}{*}{ Types } & \multicolumn{2}{|c|}{ ratio between two ships } \\
\cline { 2 - 3 } & $L_{2} / L_{1}$ & $U_{2} / U_{1}$ \\
\hline \hline Type 1 & 0.5 & $0.6,1.2,1.5$ \\
\hline Type 2 & 1.0 & $0.6,1.2,1.5$ \\
\hline Type 3 & 1.18 & $0.6,1.2,1.5$ \\
\hline
\end{tabular}

Table 3 Conditions of external force

\begin{tabular}{|c|c|c|}
\hline \multirow{2}{*}{ external force } & \multicolumn{2}{|c|}{ wind and current } \\
\cline { 2 - 3 } & direction & velocity \\
\hline \hline Wind & $0^{\circ} \sim 350^{\circ}$ & $10 \mathrm{~m} / \mathrm{s}$ \\
\hline Current & $0^{\circ}, 180^{\circ}$ & $4 \mathrm{kt}$ \\
\hline
\end{tabular}

The ship manoeuvring motions are simulated numerically by using the predicted hydrodynamic interaction forces reported in the previous research work [8] and using the ship manoeuvering model of Kijima et al. [9], and the external force and moment acting on two ships moving each other in the proximity of restricted waterways under the condition of current and wind can be expressed as follows:

$$
\begin{aligned}
& \left(m_{i}^{\prime}+m_{x i}^{\prime}\right)\left(\frac{L_{i}}{U_{i}}\right)\left(\frac{\dot{U}_{i}}{U_{i}} \cos \beta_{i}-\dot{\beta}_{i} \sin \beta_{i}\right) \\
& +\left(m_{i}^{\prime}+m_{y i}^{\prime}\right) r_{i}^{\prime} \sin \beta_{i}^{\prime}-\left(m_{x i}^{\prime}-m_{y i}^{\prime}\right) \frac{V_{c i}}{U_{i}} r_{i}^{\prime} \sin \left(\psi_{i}^{\prime}-\alpha\right) \\
& =X_{H i}^{\prime}+X_{P i}^{\prime}+X_{R i}^{\prime}+X_{W}^{\prime}
\end{aligned}
$$

$$
\begin{aligned}
& -\left(m_{i}^{\prime}+m_{y i}^{\prime}\right)\left(\frac{L_{i}}{U_{i}}\right)\left(\frac{\dot{U}_{i}}{U_{i}} \sin \beta_{i}-\dot{\beta}_{i} \cos \beta_{i}\right) \\
& +\left(m_{i}^{\prime}+m_{x i}^{\prime}\right) r_{i}^{\prime} \cos \beta_{i}^{\prime}-\left(m_{y i}^{\prime}-m_{x i}^{\prime}\right) \frac{V_{c i}}{U_{i}} r_{i}^{\prime} \cos \left(\psi_{i}^{\prime}-\alpha\right) \\
& =Y_{H i}^{\prime}+Y_{R i}^{\prime}+Y_{I i}^{\prime}+Y_{W}^{\prime}
\end{aligned}
$$

$$
\begin{aligned}
& \left(I_{z z i}^{\prime}+i_{z z i}^{\prime}\right)\left(\frac{L_{i}}{U_{i}}\right)^{2}\left(\frac{\dot{U}_{i}}{L_{i}} r_{i}^{\prime}+\frac{U_{i}}{L_{i}} \dot{r}_{i}^{\prime}\right) \\
& =N_{H i}^{\prime}+N_{R i}^{\prime}+N_{I i}^{\prime}+N_{W}^{\prime}
\end{aligned}
$$

where, $m_{i}^{\prime}$ represents non-dimensionalized mass of ship $i, m_{x i}^{\prime}$ and $m_{y i}^{\prime}$ represent $x, y$ axis components of non-dimensionalized added mass of ship $i, \beta_{i}$ means drift angle of ship $i$, respectively. The subscribt $H, P, R, I$ and $W$ mean ship hull, propeller, rudder, component of the hydrodynamic interaction forces between two ships and wind respectively, and also, $V_{c}, \alpha, \psi_{i}$ mean current velocity, current direction and heading angle of ship $i$, respectively. $X, Y$ and $N$ represent the external force of $x, y$ axis and yaw moment about center of gravity of ship, respectively. Wind forces and moments acting on ships were estimated by Fujiwara et al. [10] . A rudder angle is controlled to keep course as follows:

$$
\delta_{i}=\delta_{0 i}-K_{1}\left(\psi_{i}-\psi_{0 i}\right)-K_{2} r_{i}^{\prime}
$$

where $\delta_{i}, r_{i}^{\prime}$ represent rudder angle, non-dimensional angular velocity of ship $i$, respectively. Subscript ' 0 ' indicates initial values and also, $K_{1}$ and $K_{2}$ mean the control gain constants.

\section{Results and discussion}

\subsection{Result of simulation for ship maneu- vering motions}

In this section, the ship manoeuvring motions under the current and wind are simulated numerically using the predicted hydrodynamic interaction forces between ships while overtaking in shallow waters. Provided that the speed of a ship 1 (denoted as $U_{1}$ ) is maintained at $10 \mathrm{kt}$, the velocities of overtaking or overtaken ship 2 (denoted as $U_{2}$ ) were varied, such as $6 \mathrm{kt}, 12 \mathrm{kt}$ and $15 \mathrm{kt}$, respectively. The ratios of $\operatorname{ship} \operatorname{length}\left(L_{2} / L_{1}\right)$ selected for comparison were $0.5,1.0$ and 1.18 . 
Fig.2 shows the result of manoeuvring simulation for model ship with function of the external force for the case of 1.2 in $U_{2} / U_{1}$. In this case, the wind velocity $\left(V_{W}\right)$, current velocity $\left(V_{c}\right)$ and current direction $(\alpha)$ were taken as $10 \mathrm{~m} / \mathrm{s}, 4 \mathrm{kt}$ and $0^{\circ}$, respectively. However, the wind direction $(\nu)$ were taken as $40^{\circ}, 90^{\circ}$ and $120^{\circ}$, respectively. The separation between two ships, $S_{P 12}$, was taken as 0.3 times of $L_{1}$ and $L_{2} / L_{1}$ was taken as 1.0 in $h / d_{1}$ $=1.2$. The control gain constants used in these numerical simulations are $K_{1}=K_{2}=5.0$, and maximum rudder angle, $\delta_{\max }=10^{\circ}$. Fig. 2 indicates the following result. When and if one ship passes the other ship, any yawing moments of the overtaken vessel as shown in Fig. 2 show strong motion due to the hydrodynamic interaction forces between ships. Then once initiated such a turn would develop rapidly, the rudder force of the overtaken vessel under the condition of $\delta_{\max }=10^{\circ}$ was not large enough to stop this tendency. In case of $120^{\circ}$ of wind direction ( $\nu$ ) (Fig.2(c)), there was a most clear tendency for the overtaken vessel to deviate to starboard, compared to the cases of (a) and (b) in Fig.2. However, in case of (a) in Fig.2, two ships' courses are not almost deviated from the original direction under the condition of

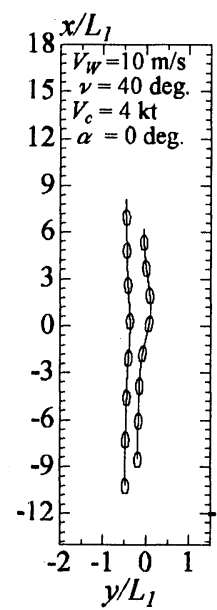

(a)

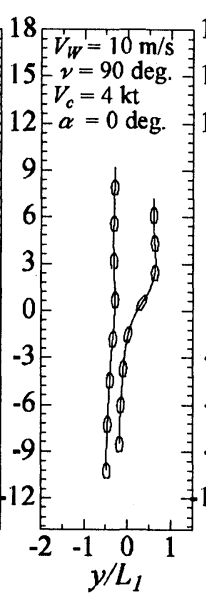

(b)

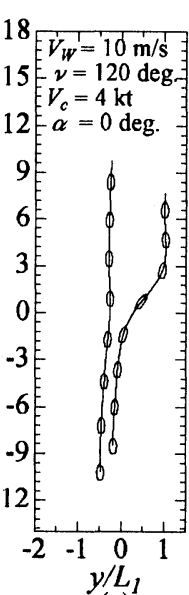

(c)
Fig. 2 Ship trajectories under the external forces with rudder control $\left(h / d_{1}=1.2, S_{P 12} / L_{1}=0.3\right.$, $L_{2} / L_{1}=1.0, U_{2} / U_{1}=1.2, K_{1}=$ $K_{2}=5.0$ )

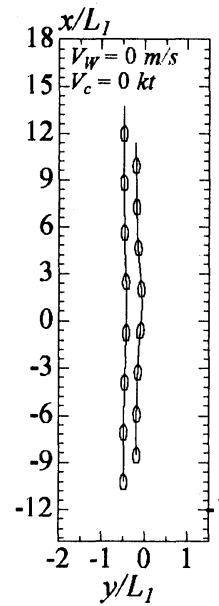

(a)

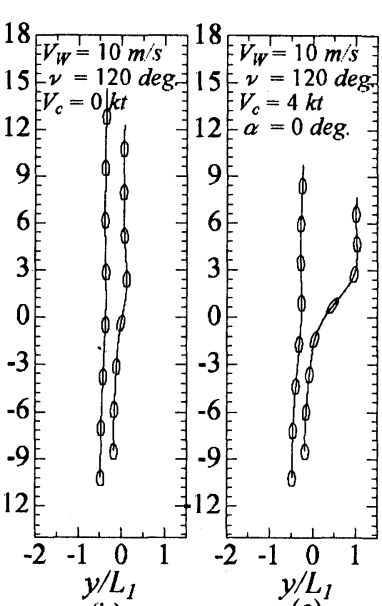

(b)

(c)
Fig. 3 Ship trajectories with function of the wind and current effect with rudder control $\left(h / d_{1}=1.2\right.$, $S_{P 12} / L_{1}=0.3, \quad L_{2} / L_{1}=1.0$, $U_{2} / U_{1}=1.2, K_{1}=K_{2}=5.0$ )

$\delta_{\max }=10^{\circ}$ because the effect of external force under the condition of $40^{\circ}$ of wind direction $(\nu)$ is not large.

Change of ship trajectories depending on the kinds of external force with rudder control are shown in Fig.3. As shown in case of (a) in Fig.3 with no consideration of external forces, two ships with maximum rudder angle of $10^{\circ}$ can navigate safely while keeping its original course even though the separation between ships is 0.3 times of $L_{1}$. In addition, as shown in case of (b) in Fig.3, considering the wind only as parameter, it indicated that two ships can steer unharmed maintaining its own original course. However, as shown in (c) of Fig.3, an overtaken vessel is pretty much deviated from the original course, which is mainly attributed to lengthening the mutual effects on their relative position between two ships if both wind and current are considered, while it is guided securely with intended direction for the overtaking vessel.

Fig.4 shows the result of time histories of heading and rudder angle for ship 1 and ship 2 with function of the separation between two ships under the conditions, that wind velocity $\left(V_{W}\right)$, current velocity $\left(V_{c}\right)$, wind direction $(\nu)$ and current direction $(\alpha)$ were taken as $10 \mathrm{~m} / \mathrm{s}, 4 \mathrm{kt}, 120^{\circ}$ and $0^{\circ}$, respectively. The control gain constants used in 

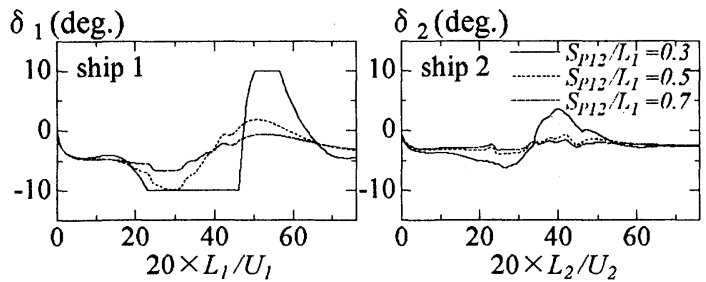

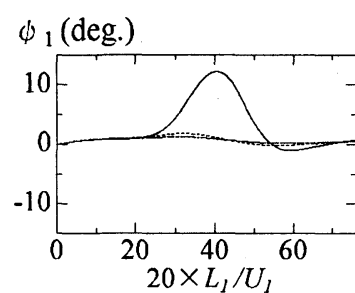

(a)

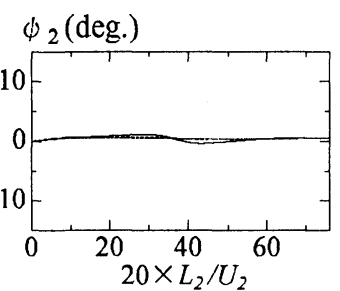

(b)
Fig. 4 Time histories with function of the separation between two ships under the external forces $\left(h / d_{1}=\right.$ $1.2, K_{1}=K_{2}=5.0, U_{2} / U_{1}=1.2$ )

these numerical simulations are $K_{1}=K_{2}=5.0$. In this case, the separation between two ships, $S_{P 12}$, were taken as 0.3 times, 0.5 times and 0.7 times of $L_{1}$ and $L_{2} / L_{1}$ was taken as 1.0 in $h / d_{1}=1.2$. Fig. 4 indicates the following result. When and if the separation between two ships is 0.3 times of ship 1 that navigate at low speed, it takes long for the ship 1 to maintain maximum rudder angle of $10^{\circ}$ in order to keep its own original course. Also, the variation of heading angle, $\psi$ gets larger in case of ship 1 . On the other hand, it is possible enough to steer the ship 2 within the range of $10^{\circ}$ in rudder angle and the heading angle, $\psi$ shows no changes for the case of ship 2. By contrast, if the distance of separation between ships is 0.5 or 0.7 times, it indicates that the heading angles, $\psi_{1}$ and $\psi_{2}$ maintain almost constant value for both ships. Of course, the steering within the maximum range of rudder angle of $10^{\circ}$ is conceivable.

\subsection{Assessment of safe navigation}

In this section, the results of assessment of safe navigation between ships moving each other in restricted waterways under the current and wind have been examined. In this segment, the computation condition for the external forces is coincident with the one of Fig.4. Fig.5 shows the result for deviated maximum lateral distance from the orig-

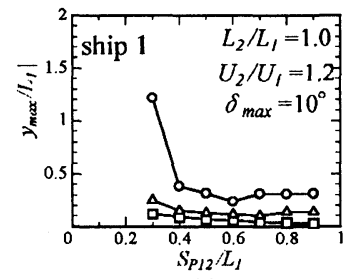

(a)

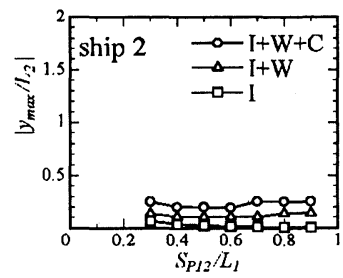

(b)
Fig. 5 Deviated maximum lateral distance from the original course with function of the external forces $\left(h / d_{1}=1.2, L_{2} / L_{1}=1.0\right.$, $U_{2} / U_{1}=1.2, \delta_{\max }=10^{\circ}$ )

inal course with function of the external forces for the case of 1.2 in $U_{2} / U_{1}$. The separation between two ships was chosen to be 0.3 to 0.9 times of $L_{1}$ under the condition of 1.0 in $L_{2} / L_{1}$. The control gain constants used in these calculations are $K_{1}=K_{2}=5.0$ and maximum rudder angle $\delta_{\max }=10^{\circ}$. In Fig.5, $I, W, C$ represent hydrodynamic interaction force between two ships, wind and current, respectively. Fig.5(a) and (b) show the result for ship 1 and ship 2, respectively. As shown in Fig.5, with no consideration of external forces, two ships' courses are not almost deviated from the original direction under the condition of $\delta_{\max }=10^{\circ}$ even though the separation between ships is 0.3 times of $L_{1}$. In addition, considering the wind only as parameter, it indicated that two ships can steer unharmed maintaining its own original course. However, an overtaken vessel is pretty much deviated from the original course if both wind and current are considered, while it is guided securely with intended direction for the overtaking vessel. On the other hand, if the lateral distance between two ships is about 0.5 times

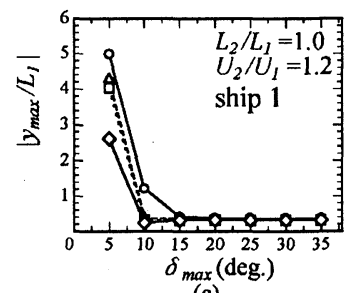

(a)

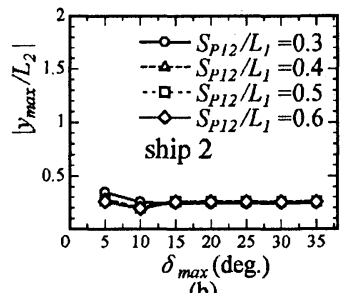

(b)
Fig. 6 Deviated maximum lateral distance from the original course with function of $S_{P 12} / L_{1}\left(L_{2} / L_{1}\right.$ $=1.0, U_{2} / U_{1}=1.2$ ) 


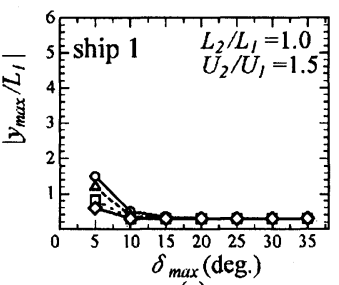

(a)

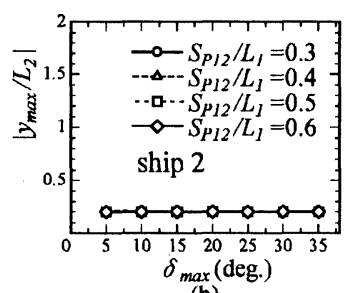

(b)
Fig. 7 Deviated maximum lateral distance from the original course with function of $S_{P 12} / L_{1}\left(L_{2} / L_{1}\right.$ $=1.0, U_{2} / U_{1}=1.5$ )

of $L_{1}$, an overtaken vessel is not pretty much deviated from the original course under the current and wind.

Fig.6 displays the result for deviated maximum lateral distance from the original course with function of the $S_{P 12} / L_{1}$ for the case of 1.2 in $U_{2} / U_{1}$. In this case, the separation between two ships, $S_{P 12}$, was chosen to be 0.3 to 0.6 times of $L_{1}$ and $L_{2} / L_{1}$ was taken as $1.0 \mathrm{in} h / d_{1}=1.2$. From Fig.6, an overtaken and overtaking vessel's course is not largely deviated from the original direction under the condition of $\delta_{\max }=15^{\circ}$ regardless of the separation between two ships. Also, if the lateral distance between two ships is about 0.5 times of $L_{1}$, an ovretaking and overtaken vessel is not pretty much deviated from the original course under the condition of $\delta_{\max }=10^{\circ}$.

The deviated maximum lateral distance from the original course with function of the $S_{P 12} / L_{1}$ for the case of 1.5 in $U_{2} / U_{1}$ is shown in Fig.7. As shown in Fig.7, the maximum lateral distance of two ships is not largely deviated from the original direction

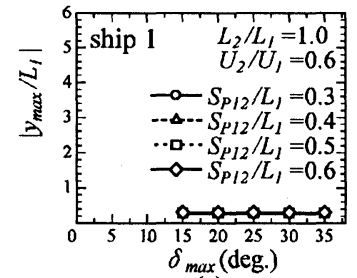

(a)

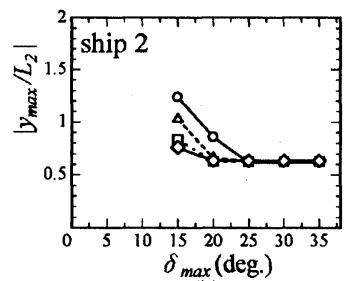

(b)
Fig. 8 Deviated maximum lateral distance from the original course with function of $S_{P 12} / L_{1}\left(L_{2} / L_{1}\right.$ $=1.0, U_{2} / U_{1}=0.6$ )

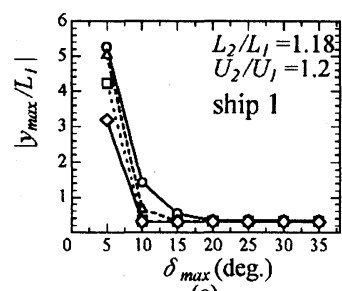

(a)

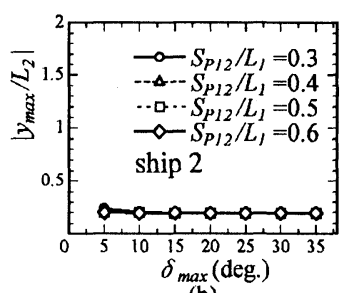

(b)
Fig. 9 Deviated maximum lateral distance from the original course with function of $S_{P 12} / L_{1}\left(L_{2} / L_{1}\right.$ $\left.=1.18, U_{2} / U_{1}=1.2\right)$

under the condition of $\delta_{\max }=10^{\circ}$ even though the separation between ships is 0.3 times of $L_{1}$.

Fig. 8 shows the result for deviated maximum lateral distance from the original course with function of the $S_{P 12} / L_{1}$ for the case of 0.6 in $U_{2} / U_{1}$. From this Fig.8, it indicates the following result. Lowspeed vessel with maximum rudder angle of $10^{\circ}$ can not navigate regardless of the $S_{P 12} / L_{1}$ because of ship collision due to insufficient rudder force corresponding to the rudder angle. Also, the low-speed vessel is potentially hazardous because the rudder force of low-speed vessel needed for steady-state course-keeping is not sufficient, compared to the high-speed vessel under the condition of $\delta_{\max }=25^{\circ}$ even though the separation between ships is 0.6 times of $L_{1}$. Accordingly, an overtaken vessel navigating at low speed should be cautioned with high alert for the case of current and wind, and it is considered that speeding up an engine is required if necessary.

The deviated maximum lateral distance from the original course with function of the $S_{P 12} / L_{1}$ for the

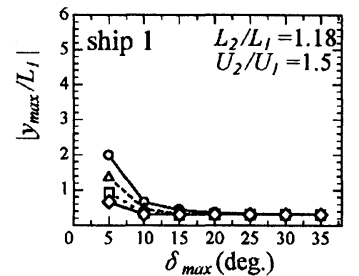

(a)

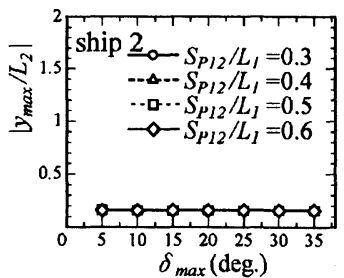

(b)
Fig. 10 Deviated maximum lateral distance from the original course with function of $S_{P 12} / L_{1}\left(L_{2} / L_{1}\right.$ $=1.18, U_{2} / U_{1}=1.5$ ) 


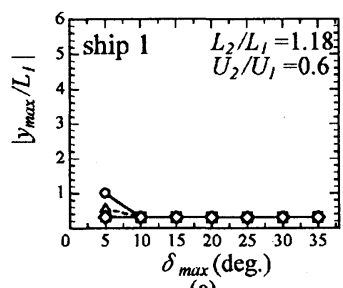

(a)

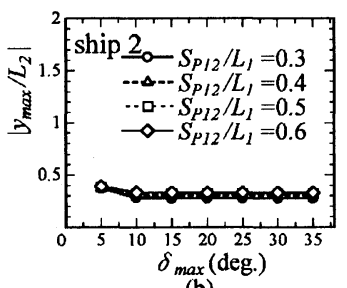

(b)
Fig. 11 Deviated maximum lateral distance from the original course with function of $S_{P 12} / L_{1}\left(L_{2} / L_{1}\right.$ $=1.18, U_{2} / U_{1}=0.6$ )

case of 1.18 in $L_{2} / L_{1}$ are shown in Fig.9, Fig.10 and Fig.11. From Fig.9, Fig.10 and Fig.11, it indicates the following result. The maximum rudder angle needed for steady-state course-keeping and lateral distance between ships are necessarily required for the velocity ratio of 1.2 , compared to the cases of 0.6 and 1.5. Also, the maximum lateral distance of two ships is not largely deviated from the original direction under the condition of $\delta_{\max }=10^{\circ}$ if the separation between ships is about 0.5 times of $L_{1}$.

Fig.12 and Fig.13 show the deviated maximum lateral distance from the original course with function of the $S_{P 12} / L_{1}$ for the case of 0.5 in $L_{2} / L_{1}$. As shown in Fig.12, in case of 0.3 in $S_{P_{12}} / L_{1}$, small vessel can not navigate regardless of the maximum rudder angle because the rudder force of small vessel needed for steady-state course-keeping is not sufficient. Also, in case of 0.4 in $S_{P 12} / L_{1}$ under the condition of $\delta_{\max }=5^{\circ}$, the small vessel can not navigate. However, the maximum lateral distance

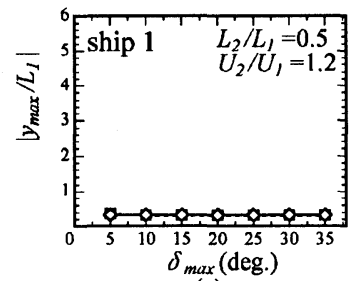

(a)

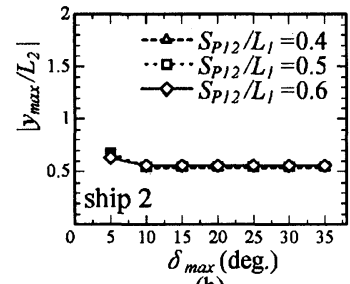

(b)
Fig. 12 Deviated maximum lateral distance from the original course with function of $S_{P 12} / L_{1}\left(L_{2} / L_{1}\right.$ $=0.5, U_{2} / U_{1}=1.2$ )

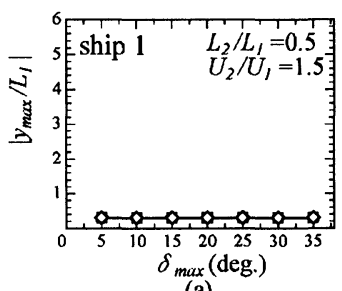

(a)

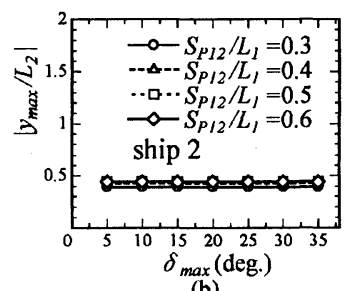

(b)
Fig. 13 Deviated maximum lateral distance from the original course with function of $S_{P 12} / L_{1}\left(L_{2} / L_{1}\right.$ $=0.5, U_{2} / U_{1}=1.5$ )

of two ships is not largely deviated from the original direction under the condition of $\delta_{\max }=10^{\circ}$ if the separation between ships is about 0.5 times of $L_{1}$.

In case of Fig.13, the maximum lateral distance of two ships is not largely deviated from the original direction under the condition of $\delta_{\max }=10^{\circ}$ even though the separation between ships is 0.3 times of $L_{1}$.

On the other hand, in case of 0.3 to 0.6 in $S_{P 12} / L_{1}$, the small vessel can not navigate under the condition of 0.6 in $U_{2} / U_{1}$ and 0.5 in $L_{2} / L_{1}$ regardless of the maximum rudder angle. Keeping the original course of navigation is largely difficult if accompanied with the external forces of current and wind, due to the higher mutual interaction forces and to the small rudder force in case of small overtaken vessel with low speed.

\section{Conclusions}

A parametric study on the numerical investigations has been conducted on the general cargo ship. From the simulation of ship manoeuvring motions on the safe navigation between ships while overtaking in shallow waters under the current and wind, the following conclusions can be drawn.

If the wind was the only factor to be considered, the course of a ship did not deviate from its intended path with ranges of less than $10^{\circ}$ in maximum rudder angle. However, the lateral distance between ships, rudder angle, and speed of a ship had a critical influence on a safe navigation when both of wind and current are regarded as parameters. 
For the length ratio of $L_{2} / L_{1}=1.0$, both the distance between two ships and the rudder angle are necessarily required in terms of safe manoeuvre in case of $U_{2} / U_{1}=1.2$ when compared to the ratio of $U_{2} / U_{1}=1.5$. In particular, for the velocity ratio of $U_{2} / U_{1}=0.6$, the low-speed vessel with ranges of 10 degrees in rudder angle can not navigate because of ship collision under the condition of 0.3 to 0.6 in $S_{P 12} / L_{1}$. Besides, the deviation for the case of low-speed vessel even with the rudder angle of 25 degrees was comparatively larger from its intended course. In this case, high-caution for the safety is needed, and the speeding up the vessel is preferable.

If the length ratio of $L_{2} / L_{1}=1.18$, the consideration of ship's distance and rudder angle is much more required for the velocity ratio of $U_{2} / U_{1}=1.2$ than for the cases of 1.5 and 0.6 , respectively. Regardless of the velocity ratio, the ship can be maneuvered safely without deviating from the original paths under the two conditions; the distance between two vessels is approximately kept at 0.5 times of ship 1 and the rudder angle should be smaller than 15 degrees.

For the case of $L_{2} / L_{1}=0.5$ with velocity ratio of $U_{2} / U_{1}=1.2$, the small vessel regardless of the rudder angle can not navigate because of ship collision if the distance between two ships is maintained at 0.3 times of ship length 1 . However, the variation from its course was not considerable provided that the distance is 0.5 times of a ship length 1 and 10 through 15 degrees of range in maximum rudder angle. Meanwhile, two vessels manoeuvred at rudder angle of 10 degrees do not show perceivable deviation from its original route for the velocity ratio of $U_{2} / U_{1}=1.5$ compared to the case of $U_{2} / U_{1}=1.2$. Furthermore, in case of 0.3 to 0.6 in $S_{P 12} / L_{1}$, small vessel steering at low speed in case of $U_{2} / U_{1}=0.6$ can not navigate regardless of the rudder angle.

As a result, when one vessel tries to overtake the small one with low steering, high-caution in terms of safe navigation is a must and the increase of velocity for those vessels steering at low-speed is demanded. Also, these results have been conducted on the general cargo ship. Therefore, a parametric study on the numerical investigations for different ship types is more required.

\section{References}

1) Yeung, R.W. : On the Interactions of Slender Ships in Shallow Water, Journal of Fluid Mechanics, Vol. 85, 1978.

2) Yeung, R.W. and Tan, W.T. : Hydrodynamic Interactions of Ships with Fixed Obstacles, Journal of Ship Research, Vol. 24, 1980.

3) Davis, A.M.J. : Hydrodynamic Effects of Fixed Obstacles on Ships in Shallow Water, Journal of Ship Research, Vol. 30, 1986.

4) Kijima, K., Furukawa, Y. and Qing, H. : The Interaction Effects Between Two Ships in the Proximity of Bank Wall, Trans. of the WestJapan Society of Naval Architects, Vol.81, 1991.

5) Kijima, K. and Qing, H. : Manoeuvering Motion of a Ship in the Proximity of Bank Wall, Journal of the Society of Naval Architects of Japan, Vol.162, 1987.

6) Yasukawa, H. : Bank Effect on Ship Maneuverability in a Channel with Varying Width, Trans. of the West-Japan Society of Naval Architects, Vol.81, 1991.

7) Lee, C.K., Kijima, K., Furukawa, Y. and Ibaragi, H. : The Sidewall Effect on the Hydrodynamic Forces Acting on a Vessel, Trans. of the West-Japan Society of Naval Architects, Vol.103, 2001.

8) Lee, C.K. and Kijima, K. : On the Safe Navigation Including the Interaction Forces Between Ship and Ship, Trans. of the WestJapan Society of Naval Architects, Vol.104, 2002.

9) Kijima, K., Nakiri, Y., Tsutsui, Y. and Matsunaga, M. : Prediction Method of Ship Maneuverability in Deep and Shallow Waters, Proceedings of MARSIM and ICSM 90, 1990.

10) Fujiwara, T., Ueno, M. and Nimura, T. : Estimation of Wind Forces and Moments Acting on Ships, Journal of the Society of Naval Architects of Japan, Vol.183, 1998. 